Article

\title{
Study of the Variations of Archaeological Marks at Neolithic Site of Lucera, Italy Using High-Resolution Multispectral Datasets
}

\author{
Athos Agapiou ${ }^{1, *}$, Vasiliki Lysandrou ${ }^{1}$, Rosa Lasaponara ${ }^{2}$, Nicola Masini ${ }^{3}$ and \\ Diofantos G. Hadjimitsis ${ }^{1}$ \\ 1 Remote Sensing and Geo-Environment Laboratory, Department of Civil Engineering and Geomatics, \\ Cyprus University of Technology, 2-8 Saripolou, Limassol 3603, Cyprus; \\ vasiliki.lysandrou@cut.ac.cy (V.L.); d.hadjimitsis@cut.ac.cy (D.G.H.) \\ 2 National Research Council, Institute of Institute of Methodologies for Environmental Analysis, \\ C.da S. Loya, Tito Scalo 85050, Italy; rosa.lasaponara@imaa.cnr.it \\ 3 National Research Council, Institute of Archaeological and Monumental Heritage, C.da S. Loya, \\ Tito Scalo 85050, Italy; n.masini@ibam.cnr.it \\ * Correspondence: athos.agapiou@cut.ac.cy; Tel.: +357-25-002-471
}

Academic Editors: Magaly Koch and Prasad S. Thenkabail

Received: 17 July 2016; Accepted: 26 August 2016; Published: 1 September 2016

\begin{abstract}
Satellite images have been systematically explored by archaeologists to detect crop marks, which are considered as a proxy for the identification of buried archaeological remains. Even though several existing algorithms are frequently applied, such as histogram enhancements and vegetation indices, the detection of crop marks still remains a difficult task, while the final interpretation results can be very poor. This paper aims to present some of the current difficulties of "remote sensing archaeology" in terms of detection and interpretation of crop marks due to the crops' phenological variations. At the same time, the presented work seeks to evaluate the recently proposed linear equations for the enhancement of crop marks, initially developed for the eastern Mediterranean region. These linear equations re-project the initial n-space spectral into a new 3D orthogonal space determined by three components: a crop mark component, a vegetation component, and a soil component. For the aims of this study, the Lucera archaeological site (southern Italy), where several Neolithic trenches have been identified, was selected. QuickBird and GeoEye high-resolution satellite images were analysed, indicating that vegetation indices may mismatch some crop marks depending on the phenological stage of the vegetation cultivated in the area of the archaeological site. On the contrary, ratios from linear equations were able to spot these crop marks even in shadow areas, indicating that improvements and developments of novel methodologies and equations based on remote sensing datasets can further assist archaeological research.
\end{abstract}

Keywords: remote sensing archaeology; crop marks; linear equations; Lucera archaeological site; vegetation indices; ratio indices; shadow areas

\section{Introduction}

Remote sensing space and ground data have been used in recent years for the identification of buried archaeological remains [1-4]. The technological improvements of satellite sensors, both in terms of spatial as well as spectral resolution, achieved within the last years, can provide archaeologists with further information regarding the landscape, assisting them to better understand and interpret large archaeological areas [5-7]. The exposure of buried archaeological features based on image processing techniques is considered a key parameter for landscape studies, while several researchers have already applied and detected hidden remains mainly through the identification of crop marks [8-13]. 
Crop marks are usually formed in regions where vegetation overlays near-surface archaeological remains. Since archaeological remains tend to retain different percentages of soil moisture in contrast to the rest of the cultivated area, spectral differences, especially in the Near Infrared (NIR) part of the spectrum, can be recorded from satellite sensors. Depending on the type of the buried archaeological features, crop vigour may be enhanced or reduced [14,15].

Nevertheless, even with the current capabilities of high-resolution satellite sensors, the detection of such crop marks faces several difficulties. A critical aspect for the true identification of crop marks is the phenological stage of the crops [16,17]. Diverse parameters, such as the weather conditions, the date of onset of greenness, the soil and crop characteristics, and the changes in the climate of an area (e.g., the length of the growing season), may cause variations in the phenological cycle of crops [18]. The latter can also affect researchers' interpretation, since features/crop marks detected from a satellite image taken during a specific phenological stage (e.g., boot stage), might be difficult to differentiate from a succeeding one taken during a different phenological stage.

In general, the detection of crop marks in vegetated areas is performed after the application of vegetation indices algorithms, which is followed by the interpretation of the images $[19,20]$. However, as demonstrated by [21,22], not all vegetation indices are suitable for the enhancement of the satellite images and identification of these marks. Researchers, aware of this mismatch of multi-temporal datasets, are seeking additional information to confirm or revoke the image signal by applying other techniques including ground geophysical surveys.

In order to overcome the above described difficulties and to improve the results of the process, many researchers have focused on the development of novel methodologies and equations. For instance, [15] identified that the optimum spectral region for detection of crop marks using hyperspectral datasets is between $700 \mathrm{~nm}$ and $800 \mathrm{~nm}$. Moreover, [23] proposed an image-based methodology to identify phenological variations linked with the presence of buried archaeological features. However, in the case of high-resolution multispectral datasets, these approaches are difficult to pursue, since narrowband wavelengths cannot be used in broadband images the same as the commercial high-resolution sensors, while the phenological observations need the acquisition of several images, which is time-consuming.

In recent years, new linear equations have been proposed in the literature by [24-26] to improve the interpretation of crop marks. These equations are linear transformations of the initial spectral bands depending on the sensor used (e.g., IKONOS, GeoEye, QuickBird, WorldView-2, etc.). For the calculation of the n-space coefficients, a four-step methodology was followed for each sensor. The linear equations re-project the initial spectral n-space into a new 3D orthogonal space determined by three components: a crop component, a vegetation component, and a soil component. The outcome of the applied transformation is a new pseudo-colour composite, which enables the improvement of the crop marks' interpretation and therefore the detection of buried archaeological remains.

In the area of Lucera in Italy, a large number of archaeological crop marks are visible in different seasons during the year, revealing evidence of long human occupation. The area has already been investigated in the past, using integrated satellite remote sensing datasets and ground geophysical techniques (see more in $[27,28]$ ). Recently, a satellite multi-temporal investigation, along with in situ analysis of the soil, has been performed by [29]. The results obtained showed that the visibility of crop marks in this site depends on many parameters including the land use, changes observed during the cycle of the agricultural cultivation, drainage capability of the soil, and specific meteorological conditions. Based on previous outcomes, this study aims to evaluate in a qualitative way the detection of crop marks via image improvement during different phenological stages, based on different enhancement techniques-including linear equations-using two high-resolution satellite images. This is considered of great interest since until now these algorithms-initially developed for the eastern Mediterranean region-have not yet been fully and critically assessed in other environments for different phenological cycles. Prior to the application and evaluation of the different image processing techniques, a short introduction to the linear equations is provided in Section 2. 


\section{Linear Equations}

Linear equations for the enhancement of crop marks have been recently proposed in the literature [24-26]. These linear equations, which have been developed for several medium- and high-resolution satellite sensors (see further details in [24-26]), provide a new 3D spectral space composed by three components: the first component (Crop Component 1; CC 1) aims to enhance crop marks in satellite images; the second component (CC 2) improves the enhancement of vegetation (i.e., cultivated crops over the area of interest); and the last component (CC 3) targets the detection of soil. The development of these equations was based upon systematic ground spectroradiometric campaigns over simulated archaeological sites during a complete phenological cycle of cereal crops in Cyprus. Hundreds of ground spectral signatures have been taken and used for this study. The methodology followed for the development of the equations was based on the work of Kauth-Thomas [30], also known as Tasseled Cap transformation (K-T algorithm), in order to detect vegetation in satellite data. The final results are linear equations for different satellite sensors. For instance, for GeoEye and QuickBird sensors (used in this study), these linear equations are expressed as

$$
\begin{gathered}
\text { Crop mark }_{\text {GeoEye-1 }}=-0.39 \rho_{\text {blue }}-0.73 \rho_{\text {green }}+0.17 \rho_{\text {red }}-0.54 \rho_{\text {NIR }} \\
\text { Vegetation }_{\text {GeoEye-1 }}=-0.35 \rho_{\text {blue }}-0.37 \rho_{\text {green }}-0.68 \rho_{\text {red }}+0.54 \rho_{\text {NIR }} \\
\text { Soil }_{\text {GeoEye-1 }}=0.08 \rho_{\text {blue }}+0.27 \rho_{\text {green }}-0.71 \rho_{\text {red }}-0.65 \rho_{\text {NIR }} \\
\text { Crop mark } \\
\text { VegickBird } \\
\text { Vegetation }_{\text {QuickBird }}=-0.39 \rho_{\text {blue }}-0.71 \rho_{\text {green }}+0.21 \rho_{\text {red }}-0.55 \rho_{\text {NIR }} \\
\text { Soil }_{\text {QuickBird }}=0.09 \rho_{\text {blue }}+0.24 \rho_{\text {green }}-0.72 \rho_{\text {red }}-0.65 \rho_{\text {NIR }} .
\end{gathered}
$$

As shown in Figure 1, crop marks can be enhanced further after the application of the linear equations compared to the initial spectral bands. The initial spectral distance between vegetation cultivated on top of buried archaeological remains (i.e., crop marks) and the surrounding cultivated area (i.e., healthy vegetation) is quite similar (Figure 1a) and therefore the detection of crop marks can be extremely difficult. However, after the application of the linear equations the spectral distance between crop marks and vegetation is maximized, particularly during the boot phenological stage of the crops (Figure 1b). The proposed linear equations may therefore transform the primary spectral feature space and maximise the spectral distance between the targets.

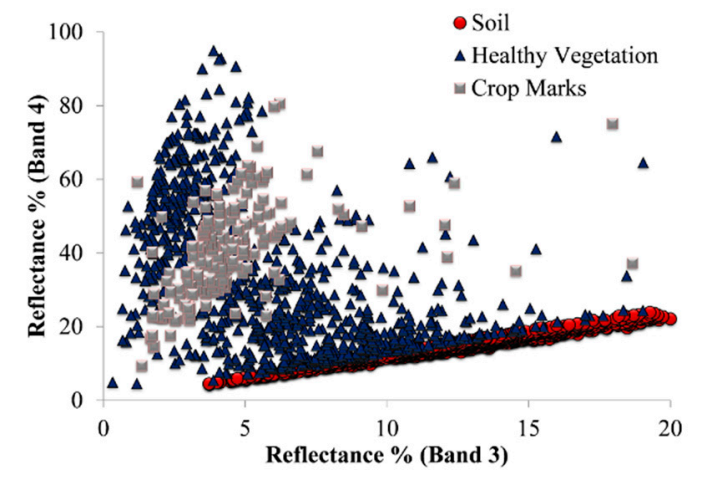

(a)

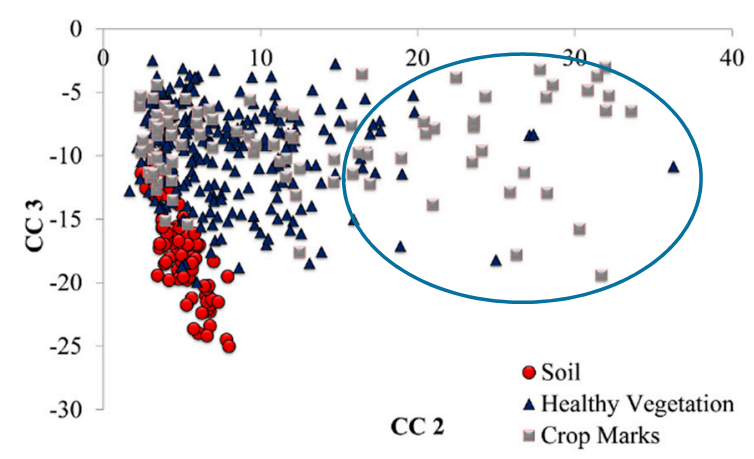

(b)

Figure 1. Improvements of linear equations for the detection of crop marks: (a) Spectral space of soil, vegetation on top of buried archaeological remains (i.e., crop marks) and the surrounding cultivated area (i.e., healthy vegetation) in the red and NIR bands; (b) the same data as (a) after the application of the linear equations during the boot stage of the crops (circled). 
The enhancements of crop marks after the application of the linear equations during the complete phenological cycle are presented in Figure 2. In this figure the variance of the three components of the linear equations is presented against the Normalized Difference Vegetation Index (NDVI). The vegetation component (CC 2) tends to have linear behaviour for the whole phenological cycle of the crops. The dynamic nature of crop marks (CC 1) is characterised through the whole phenological cycle. It is interesting to note that in higher NDVI values (i.e., in the 3rd period, when the crops are fully vegetated) these two components can be distinguished. Some higher values for the soil component (CC 3) are recorded at the beginning of the phenological cycle due to rain (wet soil). The spectral discrimination between crop marks and the rest of the cultivated areas is limited for the first two phenological periods compared to the last one.

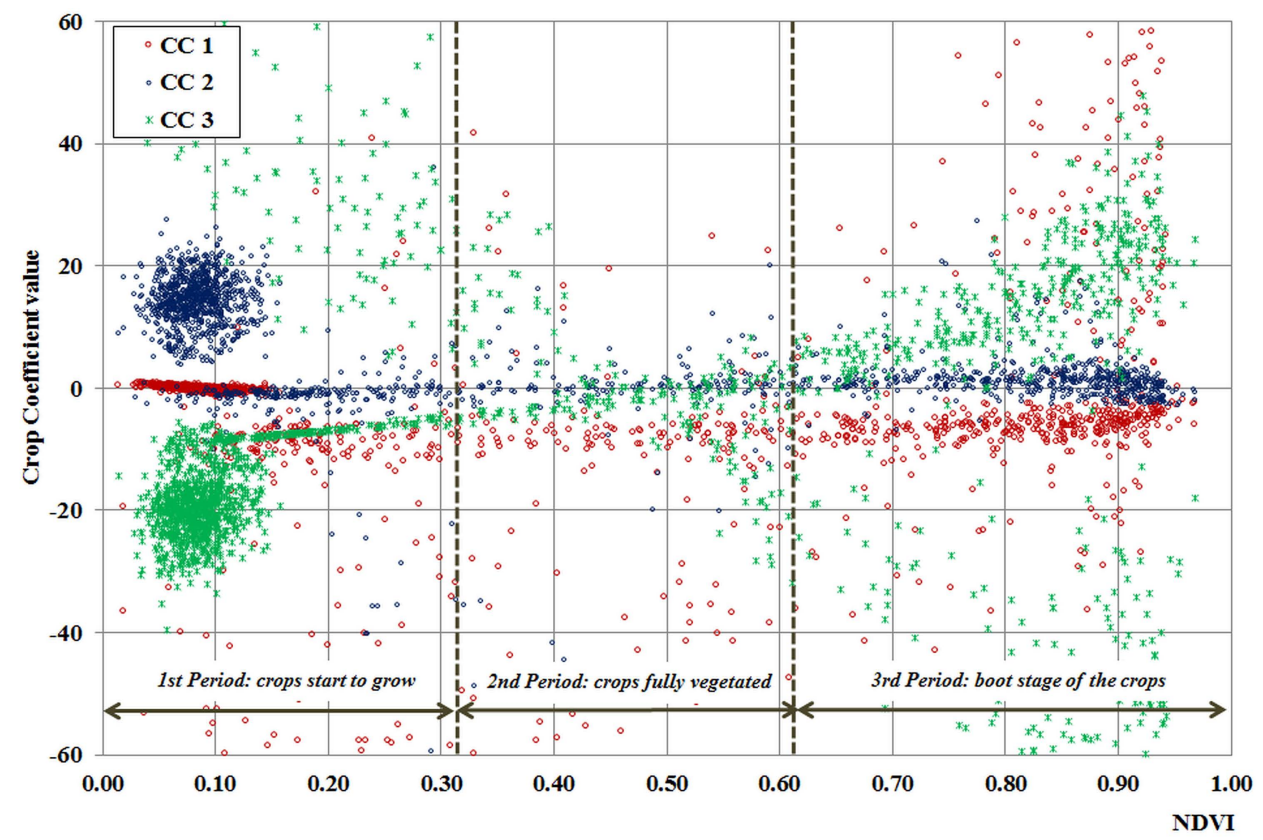

Figure 2. Variance of the three components of the linear equations is presented against the Normalized Difference Vegetation Index (NDVI): crop marks (CC 1); vegetation (CC 2); and soil component (CC 3).

\section{Case Study and Methodology}

The selected case study is of great archaeological interest and is situated in the area nearby the modern village of Lucera, in the Tavoliere territory (Apulia region, Southern Italy; see Figure 3). In this area, a large number of crop marks that reveal traces of long human habitation since the Neolithic age have been identified $[27,28]$.

In the Tavoliere territory, which covers approximately $3000 \mathrm{~km}^{2}$, the combination of the soil geo-pedological features due to its peculiar geomorphological characteristics (located between the Apennine Mountain and the Adriatic sea), type of vegetation, and agricultural practice have created special conditions for the appearance of crop marks $[27,28]$. These marks can be generally recorded from above during the spring to autumn when crops are in the growing phase.

The extraordinary interest in studying crop marks in this area is explained by the presence of a great morphological variety of traces ranging from curvilinear to linear and quadrangular shapes, linked to the different historical phases of human presence at the site. In particular, the most common features observed in the area are curved crop marks related to the Neolithic and Bronze ages, referable to settlements, enclosures, linear marks related to Roman roads, quadrangular shapes revealing the presence of Roman villas, and, finally, grids related to more recent vineyards. Today, hundreds of ancient sites from different ages are spread in the Tavoliere territory, which is evidence of the intense historical changes in the landscape, from Neolithic to modern times, including the Bronze age, Roman 
period, and Middle Ages, visible from remotely sensed imagery by means of marks and tonal variations of the vegetation.

The first remote sensing archaeological studies were conducted by Bradford using aerial photographs taken by Royal Air Force for strategic purposes, during WWII [31]. Other contributions with particular reference to Neolithic settlements have been published by Jones [32] and Gravina [33].

The investigated area includes two sites, Schifata and Palmori, both dated to the Neolithic period [34]. These sites, as is typical for the Neolithic period [34], are characterized by the presence of concentric curvilinear features referable to double-ditched enclosures with diameters ranging from about 400 to $900 \mathrm{~m}$ that formed the protection system of the Neolithic settlements (see Figure 3). Smaller circles and C-shape features (with diameters ranging from 20 to $50 \mathrm{~m}$ ) are related to ditches that bordered a compound of huts-built wooden structures (poles and beams) covered by rammed earth on the wall and straw on the roof.

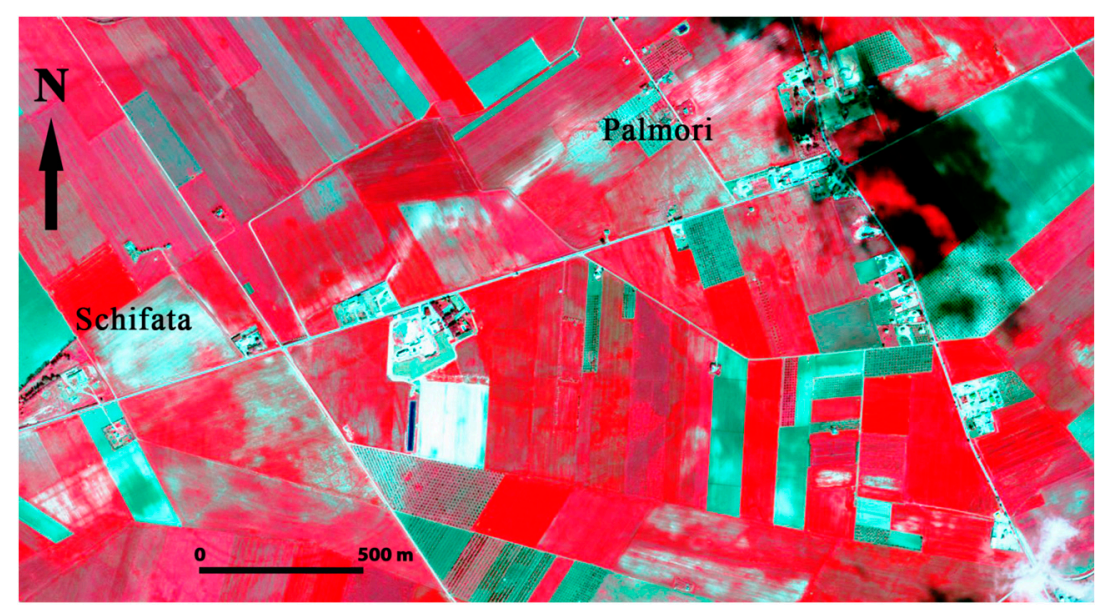

Figure 3. GeoEye false color image acquired 12 April 2012: study area including the two archaeological sites of Schifata $\left(41.540024^{\circ} \mathrm{N}\right.$ and $15.420826^{\circ} \mathrm{E}$, WGS 84$)$ and Palmori $\left(41.545551^{\circ} \mathrm{N}\right.$ and $15.436549^{\circ} \mathrm{E}$, WGS 84).

In this paper, two high-resolution satellite images have been used for the aims of this study. A GeoEye image taken on 12 April 2012 with $2.0 \mathrm{~m}$ pixel size in the multispectral bands and $0.50 \mathrm{~m}$ in the panchromatic band and a QuickBird image taken on 21 November 2007 with $2.4 \mathrm{~m}$ spatial resolution in the multispectral bands and $0.60 \mathrm{~m}$ in the panchromatic band were analysed. Figure 3 shows the NIR-R-G false colour composite of the 2012 GeoEye image.

Initially, both images were co-registered using common control points. Then, the necessary pre-processing radiometric calibration of the images was carried out using the metadata file of the images. The next step was the evaluation of some standard procedures used and applied in archaeological research, such as pseudo-colour composites and vegetation indices (NDVI and Simple Ratio (SR) indices), as well as the linear equations and ratios among the three components (vegetation/crop, vegetation/soil, and crop/soil). The final results were cross-compared with each other in terms of improvements of the interpretation for the detection of crop marks.

\section{Results}

Typical variations of the multi-temporal datasets acquired for different periods using Google Earth $\odot$ are presented in Figure 4, for the Schifata site. As is demonstrated, crop marks are mainly visible only in two out of the six images, acquired on 20 August 2010 and 12 April 2012 (see Figure 4c,d, respectively). As expected, crop marks are totally absent in Figure 4e, since the image was taken just before the seeding period. In Figure $4 \mathrm{c}$ circular and rectangular crop marks are indicated only in one 
parcel (centre of the image), while in Figure $4 \mathrm{~d}$ crop marks are visible in the entire area. For the rest of the images very few traces of archaeological interest are recorded.
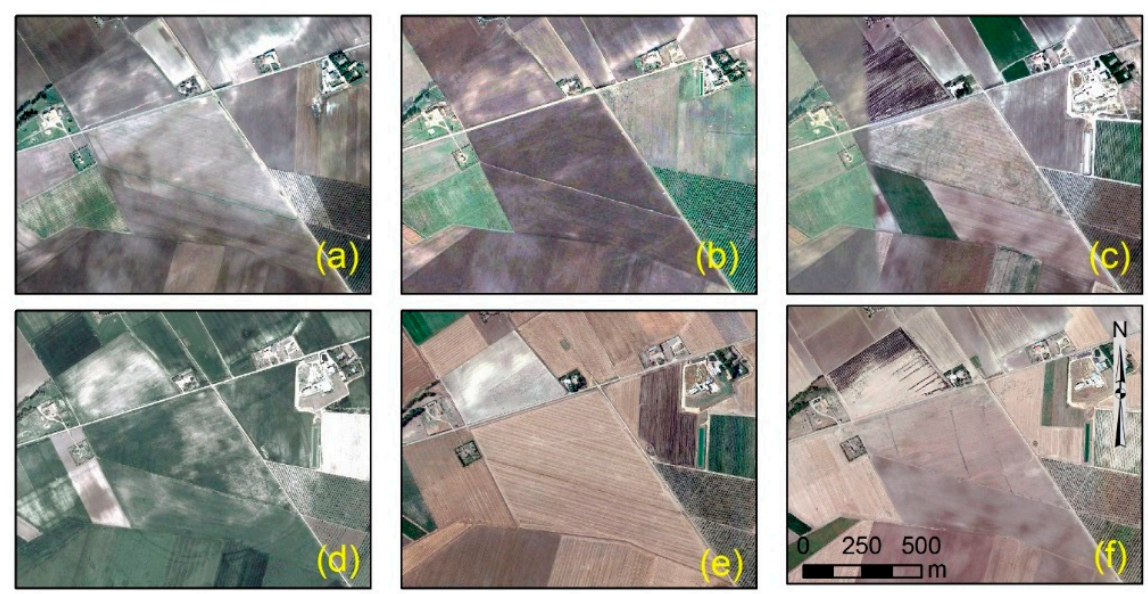

Figure 4. Schifata archaeological site. Mismatch of multi-temporal satellite images over the Neolithic site of Schifata using RGB images from Google Earth@: (a) 30 October 2002; (b) 26 November 2007; (c) 20 August 2010; (d) 12 April 2012; (e) 21 June 2013; and (f) 30 August 2015 (41.540024 N and $15.420826^{\circ} \mathrm{E}$, WGS 84).

Problems during interpretation of satellite images are mainly due to the "low" spectral signal of the traces. Indeed, phenological variation is one of the main factors that researchers have to take into account in order to exploit optical remote sensing techniques for archaeological studies. Considering the fact that in many cases satellite images used for archaeological research are archive datasets-and therefore not scheduled to be taken in the best phenophase for the detection of crop marks-it is not unusual to get poor results during image interpretation.

The NDVI index was applied to the QuickBird image over the two Neolithic settlements of Schifata and Palmori (Figure 5). Though NDVI explores the NIR and the red part of the spectrum, no crop marks can be identified due to the phenological stage of the crops, which is beyond the boot stage (Figure 5b), except for some traces in the northeast area. In contrast, several linear and circular marks are observed in the same area during April using the GeoEye image (Figure 5a).

During the cultivation period the NDVI index (Figure 6a) may provide useful results, though this index can sometimes be problematic [24]. Linear equations applied to the same dataset (2012 GeoEye) were able to provide similar results (see Figure $6 b-d$ ), especially when the vegetation coefficient was applied. Circular shapes and other linear features are recognized in the images (Figure 6a,c,d). The interpretation may be further improved, however, by applying ratios. Figure 7a-d demonstrate the results after applying the crop/soil ratio, vegetation/crop ratio, vegetation/soil ratio, and NIR/red ratio (known as the simple ratio index), respectively, using the GeoEye image (for the Schifata site). Ratio images such as those of vegetation to crop (Figure 7b) and the simple ratio (Figure 7d) seem to improve the contrast between the "archaeological" marks and the surrounding cultivated areas.

Most important, however, is that the ratio images were able to "penetrate" shadow areas and reveal potential archaeological remains, as indicated in Figure 8. While in the panchromatic band (Figure 8a), no marks are detected within the shadow areas but circular trenches in the eastern part of the image can be spotted in the vegetation coefficient (Figure $8 b$ ), the NIR/red ratio (Figure $8 c$ ), and the vegetation/crop ratio (Figure $8 \mathrm{~d}$ ). These algorithms were able to maximize the local small variance between crop marks and cultivated areas, despite the small reflectance values recorded under the shadow areas. 


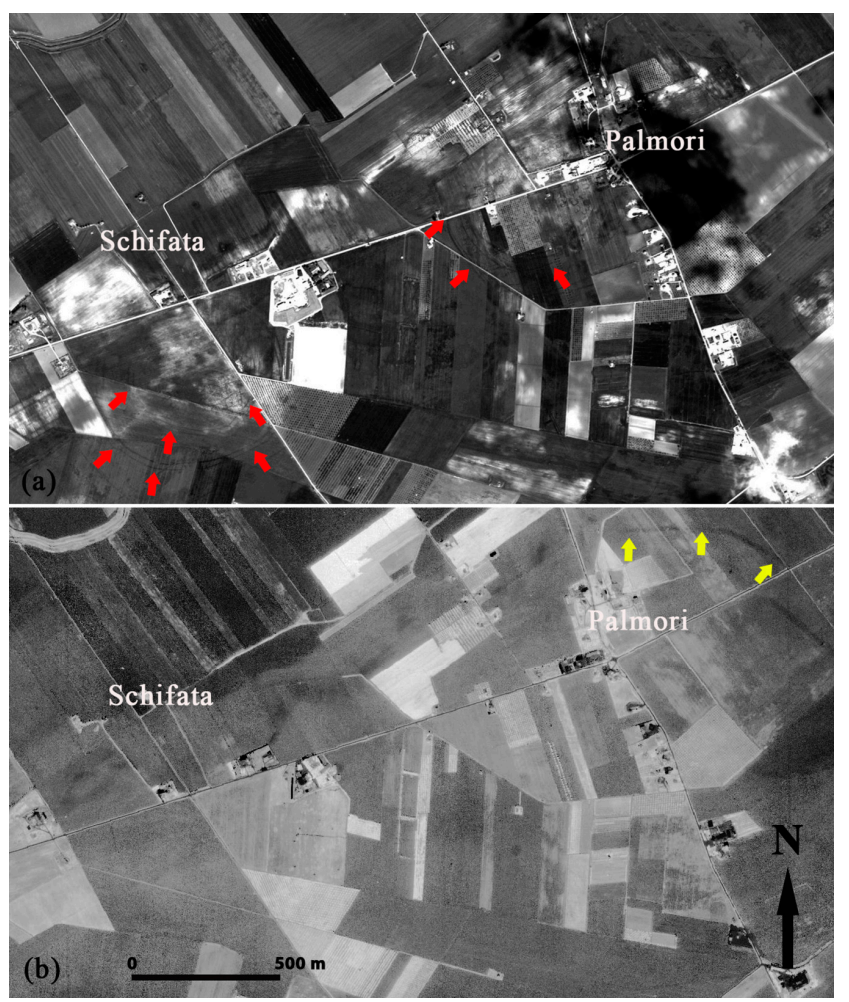

Figure 5. Schifata $\left(41.540024^{\circ} \mathrm{N}\right.$ and $15.420826^{\circ} \mathrm{E}$, WGS 84) and Palmori $\left(41.545551^{\circ} \mathrm{N}\right.$ and $15.436549^{\circ} \mathrm{E}$, WGS 84) archaeological sites. Temporal and spatial mismatch of multi-temporal satellite images over two Neolithic settlements: (a) NDVI component applied for GeoEye image acquired on 12 April 2012, indicating some circular crop marks on both of them (indicated with red arrows); (b) NDVI index applied for QuickBird image acquired on 26 November 2007. The crop marks of the scene in April 2012 are not visible in November 2007. However, in this image traces of marks in the settlement are visible in the northeast (see yellow arrows).

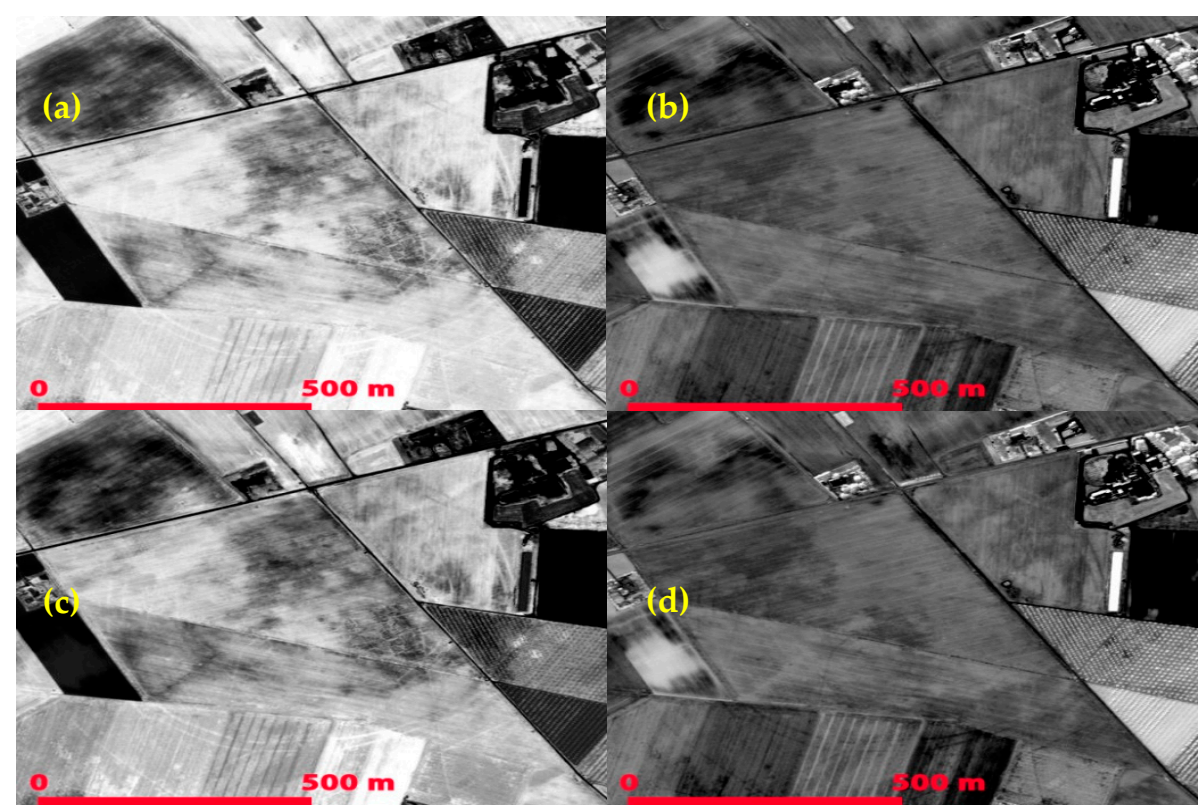

Figure 6. 2012 GeoEye, Schifata archaeological site $\left(41.540024^{\circ} \mathrm{N}\right.$ and $15.420826^{\circ} \mathrm{E}$, WGS 84). (a) NDVI index; (b) crop coefficient; (c) vegetation coefficient; and (d) soil coefficient applied in the GeoEye image. NDVI and vegetation coefficients discriminate the crop marks well. 


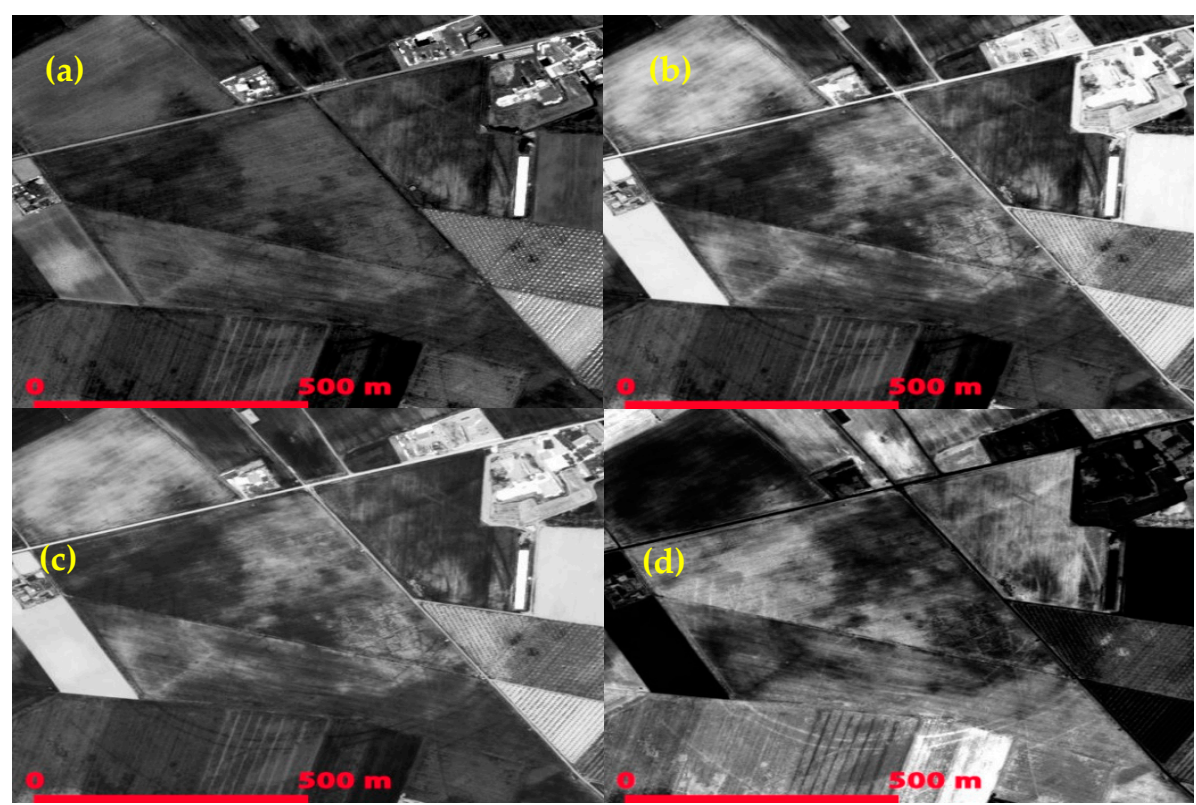

Figure 7. 2012 GeoEye, Schifata archaeological site $\left(41.540024^{\circ} \mathrm{N}\right.$ and $\left.15.420826^{\circ} \mathrm{E}, \mathrm{WGS} 84\right)$. (a) crop/soil ratio index; (b) vegetation/crop ratio index; (c) vegetation/soil ratio index; and (d) NIR/red ratio index applied in the GeoEye image. The best results in terms of visibility of crop marks are observed from $(\mathbf{b}-\mathbf{d})$.

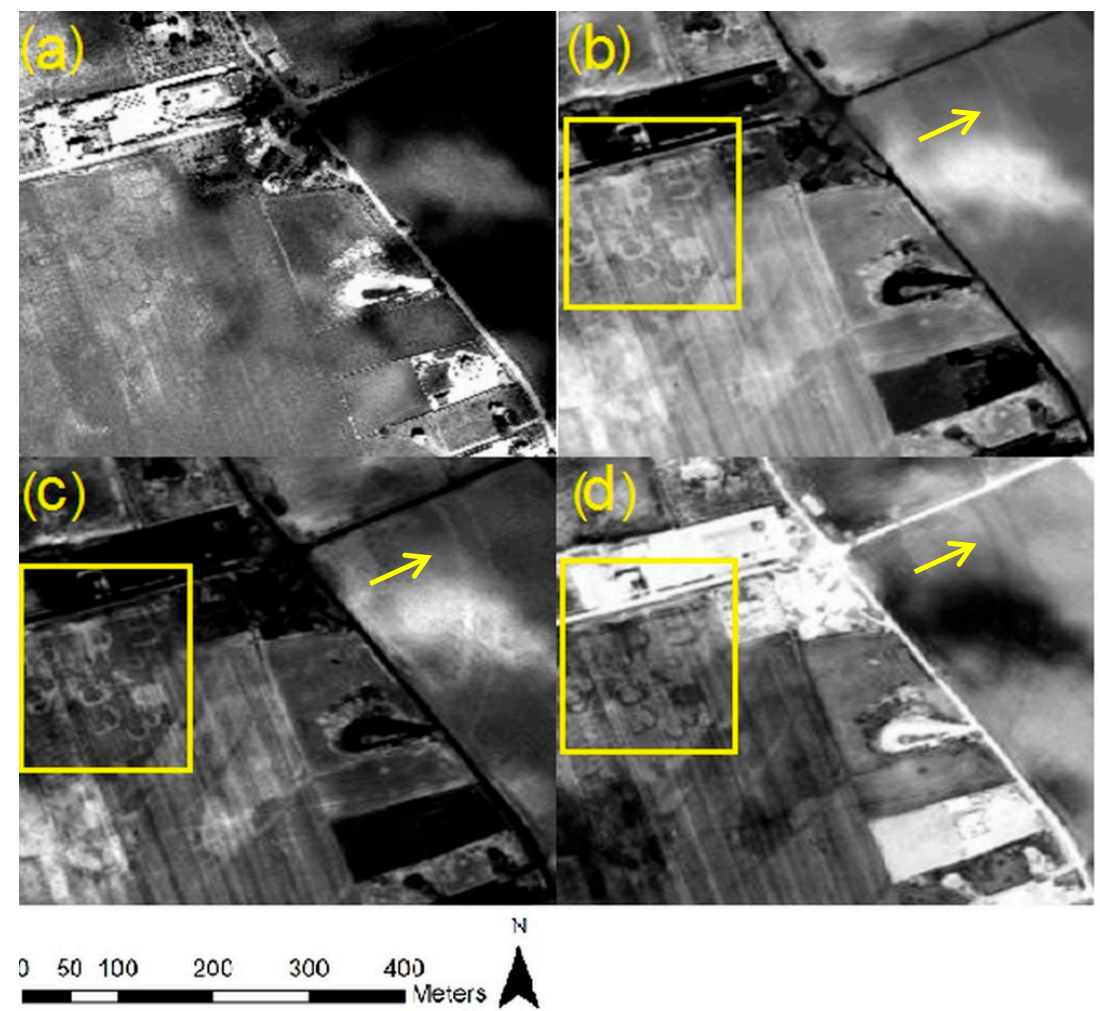

Figure 8. Palmori archaeological site $\left(41.545551^{\circ} \mathrm{N}\right.$ and $15.436549^{\circ} \mathrm{E}$, WGS 84). (a) Panchromatic band; (b) vegetation coefficient; (c) NIR/red ratio; and (d) vegetation/crop ratio applied in the 2012 GeoEye image. The vegetation coefficient and the NIR/red and vegetation/crop mark ratios are able to reduce the shadow caused by the clouds. The yellow arrows indicate part of a curvilinear mark, referable to a ditch bordering Palmori settlement. The visual comparison of Figure 5a,b shows that the features evident from the 2012 scene are not visible in the 2007 picture and vice versa. 
Other circular crop marks in Palmori were also examined, as shown in Figure 9. Although the panchromatic image seems to be able to exhibit the main features, these present noise due to oversaturation. In contrast, the NDVI, the vegetation component, and the vegetation/crop and vegetation/soil ratios seem to be able to reduce noise and enhance the circular and C-shape features.

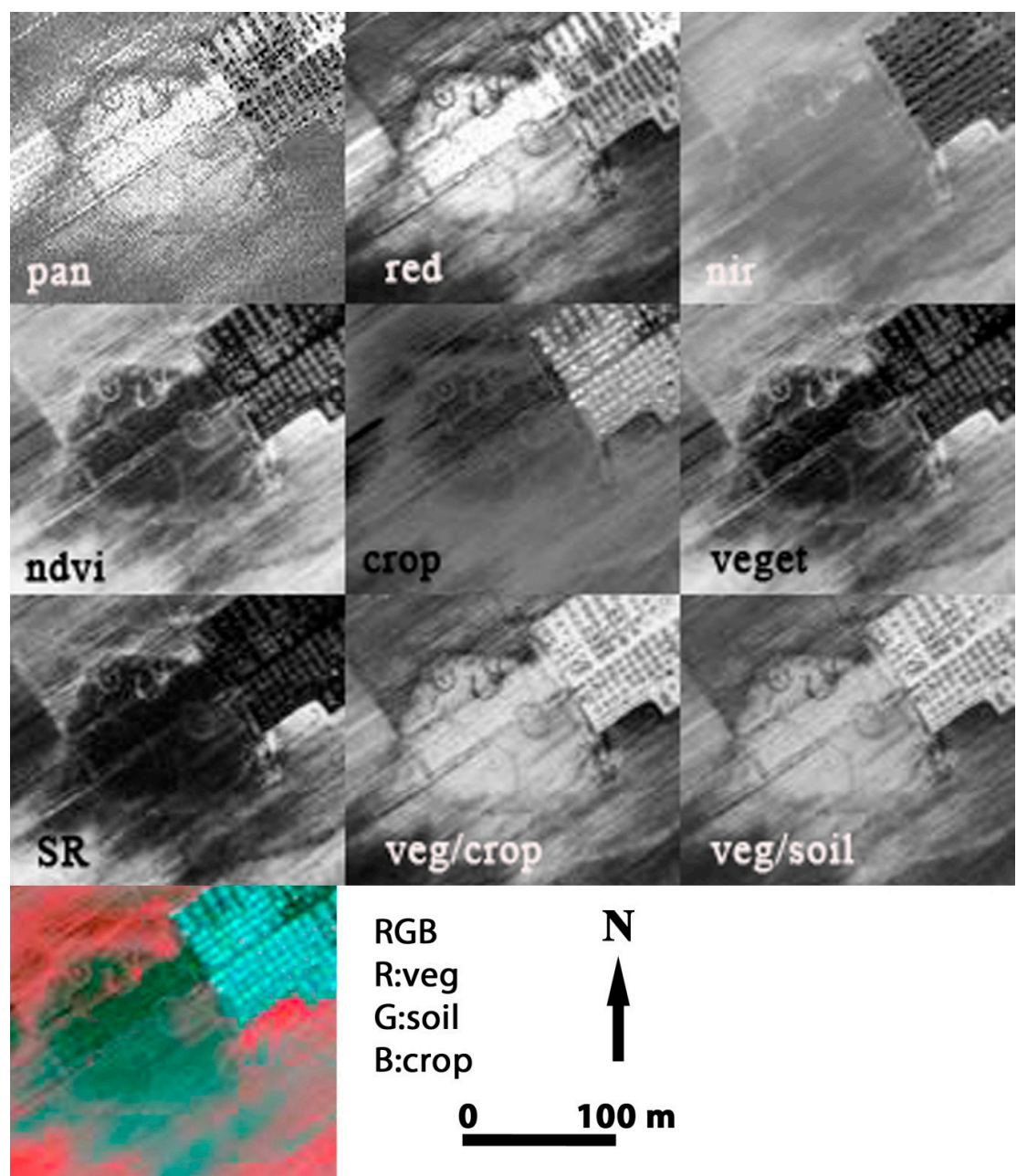

Figure 9. Palmori archaeological site $\left(41.545551^{\circ} \mathrm{N}\right.$ and $15.436549^{\circ} \mathrm{E}$, WGS 84), 2012 GeoEye image from top to bottom and left to right: panchromatic; red; NIR; NDVI; crop component; vegetation component; simple ratio; vegetation/crop ratio; vegetation/soil ratio and pseudo-colour composite of vegetation; soil and crop components. Each scene puts in evidence an oval feature, with diameter ranging from 110 to $125 \mathrm{~m}$, referable to a ditched enclosure, including smaller inner circles and C-shaped marks referable to compounds of huts.

\section{Discussion}

The results presented in the previous section show that the detection of marks can be challenging, especially when the image under examination is not suitable for their detection (e.g., not taken during the best phenophase of the crops). Sometimes, uncovering marks depends on the initial data gathered rather than the techniques themselves, applied at the post-processing stage. In addition, in other cases, standard image analysis cannot fully enhance the hidden information and therefore researchers might fail to notice evidence related to the presence of buried archaeological remains.

Indeed, as demonstrated from the results, phenological variations of the crops may affect the detection and interpretation of marks (e.g., Figures 4 and 5). Therefore, the detection of the same crop marks for verification purposes in multi-temporal remote sensing datasets can be restricted, while 
the detection of new crop marks may occasionally be limited. NDVI and ratio indices between the linear equations seem to be sufficient in order to enhance crop marks on the one hand and to reveal other hidden information that is difficult to observe through visual inspection of the raw images on the other hand. The examples given in Figures 6, 7, and 9 show that the vegetation component of the linear equations was able to improve the interpretation of archaeological marks with respect to the panchromatic and multispectral bands, whereas the best discriminability of features is obtained by the ratios of the same components, in particular veg/crop and veg/soil.

In order to evaluate the performance of the different algorithms in a quantitative way, more than 400 pixels characterized as "crop marks" and "vegetated" areas as shown in Figure 10 were marked, based on visual interpretation followed by digitization. The samples were collected randomly.

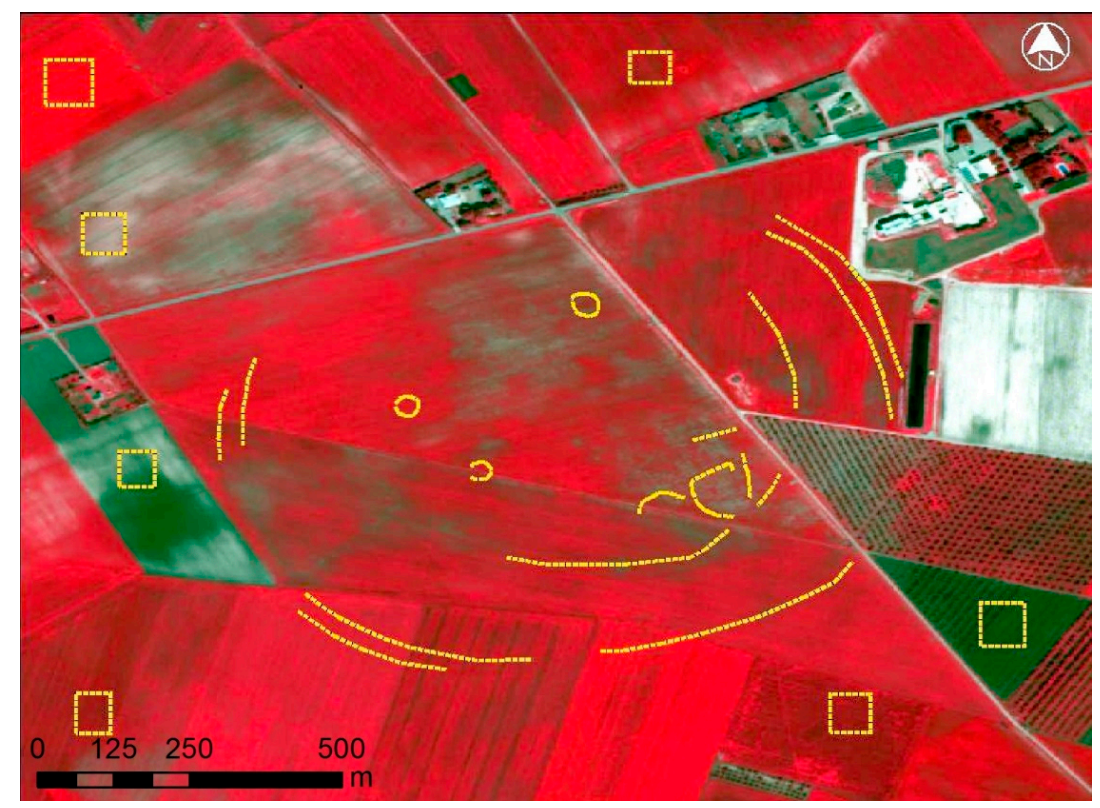

Figure 10. Areas used for assessing the performance of the algorithms: yellow lines refer to "crop marks" for both large and small marks (referable to doubled ditched enclosures and inner compounds, respectively). Yellow squares refer to "vegetated" areas $\left(41.540024^{\circ} \mathrm{N}\right.$ and $\left.15.420826^{\circ} \mathrm{E}, \mathrm{WGS} 84\right)$.

Mean values between these samples as well as maximum and minimum differences have been recorded. The overall results of this comparison is presented in Figure 11 and includes Blue; Green; Red; NIR bands; NDVI; crop mark; vegetation; and soil coefficients as well as NIR/red and vegetation/crop mark ratios over the Lucera site. The relative difference was calculated based on the following formula:

$$
\text { Relative Difference }=\left(\text { Value }_{\text {crop marks }}-\text { Value }_{\text {vegetation }}\right) / \text { Value }_{\text {crop marks }} \times 100 \text {. }_{\text {. }}
$$

In addition, the Spectral Separability Index (SSI), initially proposed by [35], was also assessed. As stated by [33], the SSI is computed considering the contrast between the archaeological features (i.e., crop marks) and their surroundings (i.e., vegetated areas) based on Equation [8]:

$$
\mathrm{SSI}=1 \mu\left(\sigma_{1}+\sigma_{2}\right),
$$

where $1 \mu, \sigma_{1}$, and $\sigma_{2}$ are the average spectral differences and standard deviation observed for two masks, one referred to archaeological features and the second related to their surroundings, respectively.

The final results demonstrated in Figure 11 indicate that among the spectral bands NIR-as expected-tends to be the most suitable for distinguishing crop marks and the surrounding vegetated 
areas. The NDVI index is able to enhance hidden archaeological information, while the vegetation component maximizes this difference (up to nearly $80 \%$ ). It is interesting to note, though, that the use of ratios (i.e., NIR/red and vegetation/crop mark) can even improve this spectral difference between crop marks and vegetated areas and therefore further assist the interpretation of the satellite images. The quantitative results agree with the visual inspection of the images.

Relative difference (\%) and SSI index

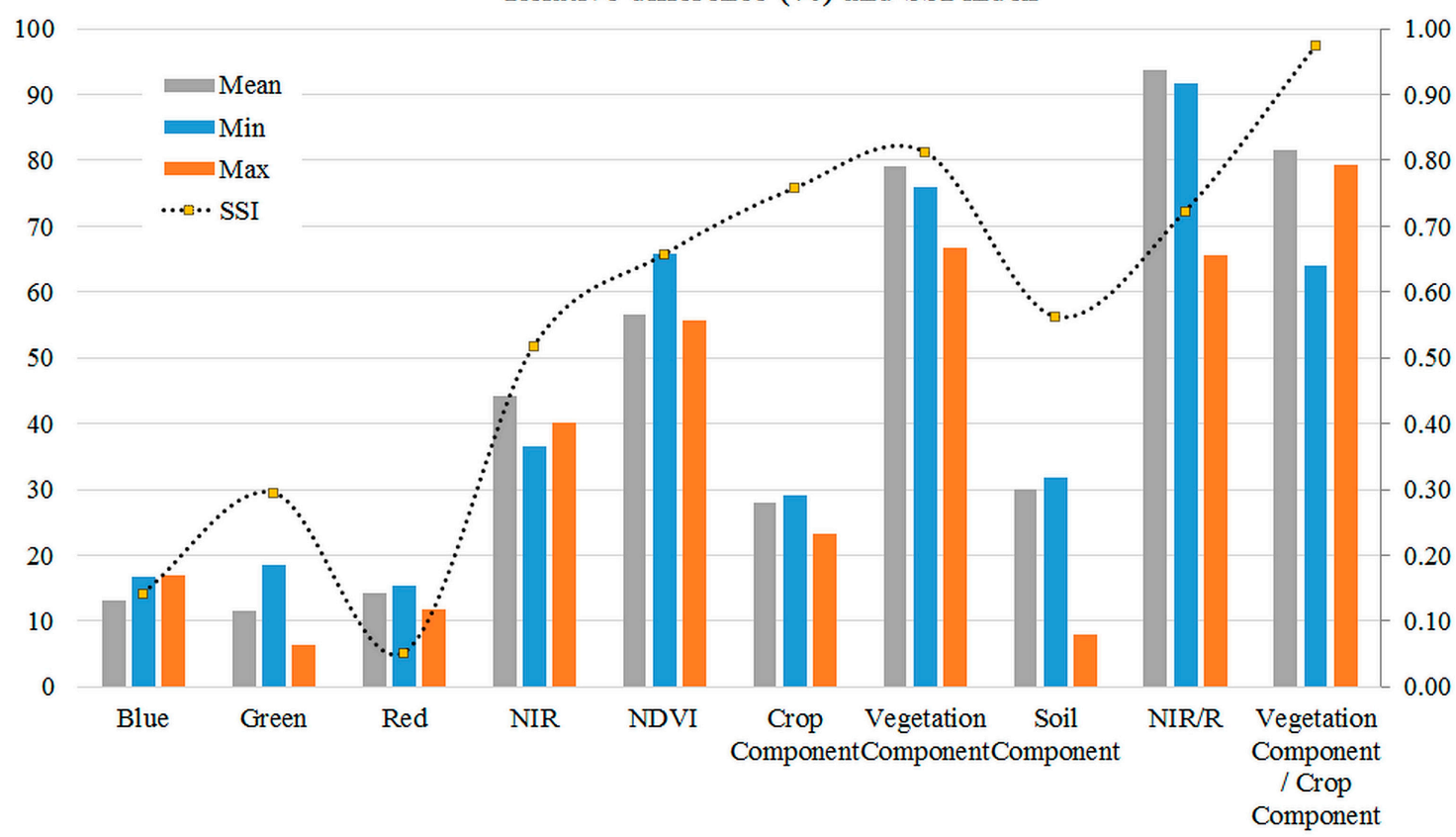

Figure 11. Relative difference and SSI index of Blue; Green; Red; NIR bands; NDVI; crop mark; vegetation; and soil coefficients as well as NIR/R and vegetation/crop mark ratios over the Lucera site.

\section{Conclusions}

Remote sensing datasets are systematically explored nowadays in archaeological research to detect buried archaeological features [6]. The detection is usually performed through interpretation of crop marks in multispectral satellite datasets. However, the application and exploitation of remote sensing images in a systematic way is still problematic as also demonstrated in this study, since in many cases crop marks are not observable in the images. Furthermore, acquisition of new high-resolution multispectral data during the best phenophase of the crops can be difficult to obtain due to budget restrictions. For this reason, many archaeological investigations usually attempt to explore archival satellite data for the detection of buried archaeological remains, as well as for better understanding the landscape of the site.

The most widely used algorithms and applications for this task in remote sensing archaeology are pseudo-colour composites and vegetation indices [6,36-38]. Despite their limitations-as these have already been discussed by several researchers $[23,26]$ — these are still applied mainly due to their simplicity. In recent years, linear equations have been also proposed by [24-26] in order to overcome some of the current difficulties/limitations of remote sensing applications in archaeological research. These linear equations can be easily applied to any type of multispectral sensor and image software by multiplying each band by the appropriate coefficient.

The purpose of the current study was to evaluate the performance of these linear equations, initially developed for the eastern Mediterranean area, in a different environment while at the same time demonstrating some of the problems related to the detection of crops. The all-inclusive outcome of the research has shown the potential use of the linear equations beyond the eastern Mediterranean. In particular, the use of ratios between the different components can improve the detection of crop 
marks even more. As demonstrated in the Lucera case study, the best discriminability of the Neolithic crop marks is obtained by the vegetation/crop and vegetation/soil ratios. In addition, these ratios were able to improve the quality of the images in shadow areas.

The overall results demonstrate that innovative equations can support archaeological research in order to enhance and facilitate the identification not only in terms of the detection of crop marks, but also in terms of archaeological interpretation at least for known archaeological sites, creating an easy way to approach large-scale areas, especially in cases where the performance of other techniques is problematic. Nevertheless, phenological variations should be taken into consideration to maximize the information retrieved from the satellite datasets. Future work is expected to be carried out by the authors in order to further improve these linear equations in other environments (e.g., northern Europe), aiming at the same time to minimize the atmospheric and soil background noise.

Acknowledgments: The present communication is under the "ATHENA" project H2020-TWINN2015 of the European Commission. This project has received funding from the European Union's Horizon 2020 research and innovation programme under grant agreement No. 691936. The satellite data have been provided by CNR-IBAM.

Author Contributions: Athos Agapiou conceived and performed the experiments; Nicola Masini and Rosa Lasaponara described the study area, contributed to the data processing and interpretation of the results. Vasiliki Lysandrou, Diofantos G. Hadjimitsis, Nicola Masini, and Rosa Lasaponara contributed substantially to the work reported.

Conflicts of Interest: The authors declare no conflict of interest.

\section{References}

1. Chen, F.; Lasaponara, R.; Masini, N. An Overview of Satellite Synthetic Aperture Radar Remote Sensing in Archaeology: From Site Detection to Monitoring. J. Cult. Herit. 2015, in press. Available online: http://dx.doi.org/10.1016/j.culher.2015.05.003 (accessed on 30 August 2016). [CrossRef]

2. Tapete, D.; Cigna, F. Trends and perspectives of space-borne SAR remote sensing for archaeological landscape and cultural heritage applications. J. Archaeol. Sci. Rep. 2016, in press. Available online: http://dx.doi.org/ 10.1016/j.jasrep.2016.07.017 (accessed on 30 August 2016). [CrossRef]

3. Savage, H.S.; Levy, E.T.; Jones, W.I. Prospects and problems in the use of hyperspectral imagery for archaeological remote sensing: A case study from the Faynan copper mining district, Jordan. J. Archaeol. Sci. 2012, 39, 407-420. [CrossRef]

4. Aqdus, A.S.; Hanson, S.W.; Drummond, J. The potential of hyperspectral and multi-spectral imagery to enhance archaeological cropmark detection: A comparative study. J. Archaeol. Sci. 2012, 39, 1915-1924. [CrossRef]

5. Giardino, J.M. A history of NASA remote sensing contributions to archaeology. J. Archaeol. Sci. 2011, 38, 2003-2009. [CrossRef]

6. Agapiou, A.; Lysandrou, V. Remote sensing archaeology: Tracking and mapping evolution in European scientific literature from 1999 to 2015. J. Archaeol. Sci. Rep. 2015, 4, 192-200. [CrossRef]

7. Lasaponara, R.; Masini, N. Series: remote sensing and digital image processing. In Satellite Remote Sensing: A New Tool for Archaeology; Springer: Berlin, Germany, 2012; Volume 16, p. 344.

8. Keay, J.S.; Parcak, H.S.; Strutt, D.K. High resolution space and ground-based remote sensing and implications for landscape archaeology: The case from Portus, Italy. J. Archaeol. Sci. 2014, 52, 277-292. [CrossRef]

9. Noviello, M.; Ciminale, M.; de Pasquale, V. Combined application of pansharpening and enhancement methods to improve archaeological cropmark visibility and identification in QuickBird imagery: Two case studies from Lucera, southern Italy. J. Archaeol. Sci. 2013, 40, 3604-3613. [CrossRef]

10. Sarris, A.; Papadopoulos, N.; Agapiou, A.; Salvi, M.C.; Hadjimitsis, D.G.; Parkinson, A.; Yerkes, R.W.; Gyucha, A.; Duffy, R.P. Integration of geophysical surveys, ground hyperspectral measurements, aerial and satellite imagery for archaeological prospection of prehistoric sites: The case study of Vésztő-Mágor Tell, Hungary. J. Archaeol. Sci. 2013, 40, 1454-1470. [CrossRef]

11. Cavalli, R.M.; Colosi, F.; Palombo, A.; Pignatti, S.; Poscolieri, M. Remote hyperspectral imagery as a support to archaeological prospection. J. Cult. Herit. 2007, 8, 272-283. [CrossRef]

12. Lasaponara, R.; Leucci, G.; Masini, N.; Persico, R.; Scardozzi, G. Towards an operative use of remote sensing for exploring the past using satellite data: The case study of Hierapolis (Turkey). Remote Sens. Environ. 2016, 174, 148-164. [CrossRef] 
13. Agapiou, A.; Alexakis, D.D.; Sarris, A.; Hadjimitsis, D.G. Evaluating the potentials of Sentinel-2 for archaeological perspective. Remote Sens. 2014, 6, 2176-2194. [CrossRef]

14. Winton, H.; Horne, P. National Archives for National Survey Programmes: NMP and the English Heritage Aerial Photograph Collection. In Landscapes through the Lens. Aerial Photographs and Historic Enviroment; Oxbow Books: Oxford, UK, 2010; pp. 7-18.

15. Agapiou, A.; Hadjimitsis, D.G.; Sarris, A.; Georgopoulos, A.; Alexakis, D.D. Optimum temporal and spectral window for monitoring crop marks over archaeological remains in the Mediterranean region. J. Archaeol. Sci. 2013, 40, 1479-1492. [CrossRef]

16. Kaimaris, D.; Patias, P. Best period for high spatial resolution satellite images for the detection of marks of buried structures. Egypt. J. Remote Sens. Space Sci. 2012, 15, 9-18. [CrossRef]

17. Agapiou, A.; Hadjimitsis, D. Vegetation indices and field spectroradiometric measurements for validation of buried architectural remains: Verification under area surveyed with geophysical campaigns. J. Appl. Remote Sens. 2011, 5, 1931-3195. [CrossRef]

18. McCloy, K.R. Development and evaluation of phenological change indices derived from time series of image data. Remote Sens. 2010, 2, 2442-2473. [CrossRef]

19. Lasaponara, R.; Masini, N. Identification of archaeological buried remains based on Normalized Difference Vegetation Index (NDVI) from Quickbird satellite data. IEEE Geosci. Remote Sens. Lett. 2006, 3, 325-328. [CrossRef]

20. Lasaponara, R.; Masini, N. Improving Satellite Quickbird-Based Identification of Landscape Archaeological Features through Tasseled Cap Transformation and PCA. In Proceedings of the 21st CIPA Symposium, Athens, Greece, 1-6 June 2007; pp. 812-816.

21. Rowlands, A.; Sarris, A. Detection of exposed and subsurface archaeological remains using multi-sensor remote sensing. J. Archaeol. Sci. 2007, 34, 795-803. [CrossRef]

22. Agapiou, A.; Hadjimitsis, D.G.; Alexakis, D.D. Evaluation of broadband and narrowband vegetation indices for the identification of archaeological crop marks. Remote Sens. 2012, 4, 3892-3919. [CrossRef]

23. Agapiou, A.; Hadjimitsis, D.G.; Alexakis, D.; Papadavid, G. Examining the phenological cycle of barley (Hordeum vulgare) using satellite and in situ spectroradiometer measurements for the detection of buried archaeological remains. GISci. Remote Sens. 2012, 49, 854-872. [CrossRef]

24. Agapiou, A.; Alexakis, D.D.; Sarris, A.; Hadjimitsis, D.G. Orthogonal re-projection of spectral bands using medium and high resolution satellite images for the detection of archaeological crop marks. Remote Sens. 2013, 5, 6560-6586. [CrossRef]

25. Agapiou, A.; Alexakis, D.D.; Sarris, A.; Hadjimitsis, D.G. Linear 3-D transformations of Landsat 5 TM satellite images for the enhancement of archaeological signatures during the phenological of crops. Int. J. Remote Sens. 2015, 36, 20-35. [CrossRef]

26. Agapiou, A. Orthogonal equations for the detection of archaeological traces de-mystified. J. Archaeol. Sci. Rep. 2016, in press. Available online: http:/ /www.sciencedirect.com/science/article/pii/S2352409X16303546 (accessed on 30 August 2016).

27. Gallo, D.; Ciminale, M.; Becker, H.; Masini, N. Remote sensing techniques for reconstructing a vast Neolithic settlement in Southern Italy. J. Archaeol. Sci. 2009, 36, 43-50. [CrossRef]

28. Ciminale, M.; Gallo, D.; Lasaponara, R.; Masini, N. A Multiscale approach for reconstructing archaeological landscapes: Applicationsin northern Apulia (Italy). Archaeol. Prospect. 2009, 16, 143-153. [CrossRef]

29. Sabia, C.; Masini, N.; Lasaponara, R. On the visibility of crop marks through seasons preliminary results from multi-date Google Earth pictures and ground truth. In Earth Observation: A Window on the Past, Proceedings of the 4th EARSeL Workshop on Remote Sensing for Cultural Heritage, Matera, Italy, 6-7 June 2013; Lasaponara, R., Masini, N., Biscione, M., Hernandez, M., Eds.; EARSeL and CNR IBAM/IMAA Publishers: Potenza, Italy, 2013; pp. 377-388.

30. Kauth, R.J.; Thomas, G.S. The Tasseled cap-A graphic description of the spectral-temporal development of agricultural crops as seen by Landsat. In Proceedings of the Symposium on Machine Processing of Remotely Sensed Data, West Lafayette, IN, USA, 29 June-1 July 1976; pp. 44-51.

31. Bradford, J.S.P. Buried landscapes in southern Italy. Antiquity 1949, 23, 58-72. [CrossRef]

32. Jones, G.D.B. Apulia-Vol. I: Neolithic Settlements in the Tavoliere; Thames and Hudson: London, UK, 1987.

33. Gravina, A. Caratteri del Neolitico Medio-Finale Nella Daunia Centro-Meridionale-6 Convegno Nazionale Sulla Preistoria-Protostoria-Storia della Daunia; Civica Amministrazione: San Severo, Italy, 1984. 
34. Guaitoli, M. Lo Sguardo di Icaro: Le Collezioni dell'Aerofototeca Nazionale Per la Conoscenza del Territorio; Campisano Editore: Roma, Italy, 2003.

35. Masini, N.; Lasaponara, R. Evaluation of the spectral capability of Quickbird imagery for the detection of archaeological buried remains. In Proceedings of the 2nd International Conference on Remote Sensing in Archaeology, Rome, Italy, 4-7 December 2006; pp. 21-29.

36. Parcak, S.H. Satellite Remote Sensing for Archaeology; Routledge Taylor and Francis Group Press: London, UK, 2009; p. 320.

37. Masini, N.; Lasaponara, R.; Orefici, G. Addressing the challenge of detecting archaeological adobe structures in southern Peru using QuickBird imagery. J. Cult. Herit. 2009, 10, 3-9. [CrossRef]

38. Bennett, R.; Welham, K.; Hill, R.A.; Ford, A.L.J. The application of vegetation indices for the prospection of archaeological features in grass-dominated environments. Archaeol. Prospect. 2012, 19, 209-218. [CrossRef]

(C) 2016 by the authors; licensee MDPI, Basel, Switzerland. This article is an open access article distributed under the terms and conditions of the Creative Commons Attribution (CC-BY) license (http://creativecommons.org/licenses/by/4.0/). 